\title{
Research of the Innovative Model of the Medium Small Enterprise in the Big Data Conditions
}

\author{
Zhihong Li* \\ Business School \\ Jianghan University \\ Wuhan, China 430056
}

\begin{abstract}
The big data are evolving so fast that they have been deeply affecting the social production and life in recent year. The quick development of the big data can't keep away from the correspondent technology like network, information, cloud computation and artificial intelligence, etc. All these changes are playing an important role in the business. In the big data conditions, to be survival, the medium small enterprise must change itself to adapt to these conditions. Considering this, the paper first expounds the characteristic of the big data conditions by analyzing the relative documentary, then explores the influence of the big data conditions to the medium small enterprise, finally proposes some innovative models in production, service, etc. to further develop the medium small enterprise in the big data conditions.
\end{abstract}

Keywords-innovative models; big data conditions; medium small enterprises

\section{INTRODUCTION}

In recent years, the rapid growth of the internet, cloud computation and internet of things, etc. promotes the coming of the big data times. The big data have influenced all walks of life like production, operation and people's life and been widely concerned. Also, the big data have become the power to stimulate the further development of the business. In the field of the production \& operation, the large quantity of the data resources during the cycle of the innovative product idea and design, manufacturing, sales and maintenance and so on include various structural and non-structural data such as text, image and video,etc. All these data are of valuable sense to the business. In the aspect of the people's life, the big data have brought much convenience and value to people because of the extensiveness, economy, accessibility and trace-ability. The medium small enterprises have been playing more and more important role in the economy and social life in China. It is an issue that can't be avoided for the medium small enterprise how to adapt itself to the conditions of the big data.

\section{FEATURES OF THE BIG DATA CONDITIONS}

The big data refer to the technology or skills with which the massive data are processed and also the benefits produced ${ }^{[1]}$. In the big data environment, the figure becomes the main media for the processing, flow and exchange of various visible or invisible resources. The typical feature of the big data environment is the figure culture that is changing the activity of the human being. The details are embodied as follows:
First, unlimited changeability. Whether in people's life or in technology or in others, endless change is the common state. And such kind of change speeds up and moves upwards indirectly. According to some research, the shelf life of the most important technology is shorter and shorter ${ }^{[2]}$. Then easy accessibility. The information platform based on the big data technology is convenient for people to get what they want once they have registered on it at any time. This greatly reduces the cost of the business. It is unnecessary to take these data as their own, but they can be used conveniently, for instance, no warehouse by Alibaba and no real estate by Airbnb. Next, timeliness. The big data and internet make it possible for us to talk with each other instantly. The timely communication tools like WeChat give people much convenience to interact in different nations or regions by video or audio, etc. All these have extended the sense ability. Also, transferability. The wide application of the big data is moulding a sharing culture either in economy or in technology or even in governmental governance, etc. This sharing atmosphere has been popularized globally. Besides, owing to its intelligent traceability, the big data technology has been extensively used in the fields like medical, ocean exploration, space probe and everyday supervision of office or public place, etc.

\section{INFLUENCE ON THE MEDIUM SMALL ENTERPRISE FROM THE BIG DATA CONDITIONS}

The technological upgrade in the big data conditions has no end, which is changing the business model ${ }^{[3]}$. In the field of cognition, the quick development application of the artificial intelligence has brought a radical change to the market. The artificial intelligence is substituting the human labor forces, which is making people losing their job. What people can't do can be done by the artificial intelligence such as CT scanning,etc. With the extensive application of the new technology in the production and operation, the artificial intelligence is applied either in the processing aspect or in the service sector in place of people. In this way, the production \& operation in the enterprise should match the progress in the business model ${ }^{[4]}$. Therefore, how to use the new technology and the artificial intelligence is the core of the survival of the medium small enterprise.

Besides the new technology like the artificial intelligence, the others in the big data conditions also have remarkable effects on the medium small enterprise. Take it for example, the development of the information technology has been 
greatly raising the security and efficiency of the production and operation $^{[5]}$ due to its easy availability. Also, the trace technology of the massive data do many benefits to the marketing activities. It can help the enterprise to locate the valuable information in the market so as to find out the consumer's preference to the output and provide exactly what the consumer wants. What's more, it can reduce much marketing cost for the enterprise, for instance the online promotion $\operatorname{cost}^{[6]}$

Naturally, the new technology in the big data conditions brings us welfare and also adverse. It is a double-edged sword. The high mobility and copy caused by the information network gives a heavy attack to the originality. The wide use of the artificial intelligence is robbing people of their employment. Such kind of things may be beyond our imagination. But no matter what happens, what the medium small enterprise can do is to remould itself and adapt to the change in the big data conditions.

\section{InNOVATIVE Models OF THE MEDIUM SMALL ENTERPRISE IN THE BIG DATA CONDITIONS}

First, the digitization of the market demand drives the digitization of the business model ${ }^{[7]}$. The big data have penetrated people's clothing, food, shelter and transportation. The market demand is being digitized. To satisfy the consumer's digitized need, whether the product development or the operational \& service model ought to be digitized, too.

Then, in order to meet the need of the digitized business, the medium small enterprise must speed up the integration between the information and industrialization. The big data in the production are the key to the digitization of the business service $^{[8]}$. Various structural and non-structural data such as text, audio and video,etc originated in the product design, making, sales and maintenance,etc mean much in the development of the medium small enterprise. They can be used to push the deep integration of the information technology and industrialization in the different sections of the industrial chain like $R \& D$, processing, operational management, marketing and after-sales service,etc. They are promoting the business competition by way of the information networking and intelligence $^{[9]}$. Take it for example, the core technology of Industrial 4.0 from German or the Making 2025 in China is that from the big data..

Next, the adaptive management model ought to be innovated ${ }^{[10]}$ because the boundary between the production and service has been blurred out. The digitization in the production field is making the service sector transferred to the direction of networking and intelligence. The latter is intensifying the blurring of the production and service. The development and application of the intelligent manufacturing is a continuous innovation in technology. The boundary among the traditional industries is being broken through and the trans-fields innovation and the novel production \& operation model is full of vigour, for example, the synergy networking design in aviation, automobile and transportation; the personified customization in clothing, home furnishings and cars; the distant operation and maintenance in electric equipment and mechanic engineering and so forth. The productive service is overwhelming with the deep development of the big data technology in internet, intelligence and internet of things, etc

\section{CONCLUSION}

The big data are affecting the business development more and more widely and deeply than ever before. The medium small enterprise in China is obliged to change itself either in the business model or in the production style or in the service field or all. It should take advantage of the concerned technology in the big data conditions to accelerate its innovation in the digitization, networking, intelligence and service so as to be survived in this fierce competitive world.

\section{ACKNOWLEDGMENT}

The paper is funded by the Discipline Group of the Integrative Management Between Economy and Industry in the City Circle, by the Wuhan Studies Institute, Hubei, China (IWHS20172001), and by Research Center on the Development of the Manufacturing Industry of the Wuhan City Circle, China (wz201607).

\section{REFERENCES}

[1] Keri E. Pearlson, Carol S.Saunders, Dennis F. Galletta, Managing \& Using Information Systems- A Strategic Approach, Wiley Binder Version,Sixth Edition, P299.

[2] Kevin Kelly. The Inevitable, VIKING, Penguin Random House LLC, 2016.

[3] Rongrui Yu. Study on the Network Marketing Tactics for the Medium Small Enterprise Under the Big Data. Human Resources Management, no.7, 2017, pp14-16

[4] Xiaowen Hou. Research of the Marketing Style of the Medium Smal Enterprise in the Times of the Big Data. Market Weekly (Theoretic Edition), no.18, 2018

[5] Ying Kong. Analysis of the Network Marketing Tactics for the Medium Small Enterprise Under the Big Data.Modern Information Economy, no. 23,2015

[6] Zhiping Ma. Choice of the Marketing Innovative Way for the Medium Small Enterprise in the Times of the Big Data.Commercial Times, no.4, 2015, pp62-63.

[7] Wenying Zeng. Analysis of the Development Chance and Countermeasures for the Medium Small Enterprise in the Times of the Cloud Computation and Big Data. Industrial \& Science Tribune, no.14,2016, pp14-15.

[8] Nan Yu. Research of the Tactics to Develop the Medium Small Enterprise in the Times of the Big Data. Science Innovation Guide, no.7 2017, pp119-120.

[9] Hao Yang. Tactics to Raise the Competitive Forces of the Medium Small Enterprise Under the Big Data Conditions. Journal of Yan'an Vocational Technological College, no.5, 2015, pp10-11.

[10] Yanliang Zhang. Innovation of the Management Model for the Enterprise in the Conditions of the Big Data.Research of the Economy and Social Development, no.3, 2015, pp148-148 